\title{
Single-port versus multi-port laparoscopic surgery for colon cancer in elderly patients
}

\author{
MASAYOSHI TOKUOKA, YOSHIHITO IDE, MITSUNOBU TAKEDA, HAJIME HIROSE, YASUJI HASHIMOTO, \\ JIN MATSUYAMA, SHIGEKAZU YOKOYAMA, YUKIO FUKUSHIMA and YO SASAKI
}

Department of Surgery, Yao Municipal Hospital, Yao, Osaka 581-0069, Japan

Received February 12, 2015; Accepted March 22, 2016

DOI: 10.3892/ol.2016.4802

\begin{abstract}
The safety of single-incision laparoscopic surgery (SLS) in elderly patients with colorectal cancer has not been established. The aim of the current study was to compare the outcomes of SLS and multi-port laparoscopic surgery (MLS) and to assess the feasibility of SLS in colorectal cancer patients aged $\geq 70$ years. A retrospective case-control study of colon cancer patients undergoing elective surgical intervention between 2011 and 2014 was conducted. A total of 129 patients with colon cancer underwent surgery and were included in the analysis. Data regarding patient demographics, surgical variables, oncological outcomes and short-term outcomes were evaluated for statistical significance to compare MLS $(n=79)$ and SLS $(n=50)$ in colon cancer patients. No significant differences were observed in patient characteristics. No case required re-admission within 30 days post surgery. The mean surgery times were similar for the MLS and SLS groups when cases with left and right hemicolectomies were combined (207.7 and $215.9 \mathrm{~min}$, respectively; $\mathrm{P}=0.47$ ). In addition, overall perioperative outcomes, including blood loss, number of lymph nodes harvested, size of the surgical margin and complications, were similar between these groups. Thus, we suggest that SLS can be performed safely in elderly patients with colon cancer.
\end{abstract}

\section{Introduction}

Colon cancer is a major cause of mortality worldwide, and is the leading cause of cancer-associated mortality in a number of developed countries (1). The number of colon cancers requiring surgical intervention continues to increase due to the prolongation of life expectancy in many nations (2). Recently, multi-port laparoscopic surgery (MLS) has been

Correspondence to: Dr Masayoshi Tokuoka, Department of Surgery, Yao Municipal Hospital, 1-3-1 Ryuge, Yao, Osaka 581-0069, Japan

E-mail: mtokuoka1017@yahoo.co.jp

Key words: single-incision laparoscopic surgery, elderly patients, reduced-port surgery adopted more frequently worldwide for the treatment of colon cancer. Compared with open surgery, MLS has been associated with less pain, a quicker recovery of gastrointestinal function, improved pulmonary function, shorter hospital stays and a better postoperative quality of life (3). In addition, single-incision laparoscopic surgery (SLS) has been successfully introduced for colon cancer treatment (4-8), and has become a more commonly used surgical option.

These procedures, when used for elderly patients, must be selected with care, considering the magnitude of the surgery and the predicted risk of hospital mortality $(9,10)$; however, postoperative morbidity and mortality increase with age (11-15). Several studies have reported that MLS demonstrates oncological results and surgical outcomes comparable to that of open surgery (16-23). However, in the elderly, although MLS is reported to be non-inferior to the open procedure and may be an acceptable alternative in elderly patients with colorectal cancer (24), no study has investigated the feasibility of SLS in elderly patients with colon cancer, with the exception of one small study (10). Therefore, the critical issue of whether SLS can benefit colon cancer patients of advanced age as an alternative to MLS remains to be elucidated. The purpose of this retrospective study was thus to determine the feasibility of SLS in the elderly.

\section{Materials and methods}

Patients. Between January 2011 and September 2014, 378 patients underwent laparoscopic surgery for colon cancer at Yao Municipal Hospital (Yao, Japan); 129 were aged $\geq 70$ years. A retrospective case-control study of these 129 patients who underwent elective surgical intervention for colon cancer was conducted. The MLS group consisted of 79 patients in the first half of this period, and the SLS group consisted of 50 patients in the latter half of this period. All procedures were performed by staff colorectal surgeons who were highly experienced in MLS or SLS. Data on patient demographics, body mass index (BMI), American Society of Anesthesiologists (ASA) class, tumor location, tumor size, personal history of prior surgery, surgery time, estimated blood loss, number of lymph nodes harvested, length of the resected margin, conversion to open surgery, insertion of an additional port, perioperative complications, morbidity and length of hospital stay were compared. The present study was 
approved by the research ethics committee of Yao Municipal Hospital. Written informed consent was obtained from the patients for publication of the present study and accompanying images.

Surgical technique. MLS required five ports, with the first 12-mm trocar in the umbilicus or a Lap Protector (LP; Hakko, Co., Ltd., Nagano, Japan) as a camera port, another 12-mm trocar, and three $5-\mathrm{mm}$ trocars. The trocars were inserted in the upper and lower abdominal quadrants on the right and left sides, under laparoscopic guidance. The camera port was expanded to extract the specimen through an incision of $4-5 \mathrm{~cm}$, as previously described $(17,25)$.

For SLS, an LP was inserted through a $30-\mathrm{mm}$ incision at the umbilicus. Following this, an EZ Access (Hakko Co., Ltd.) was mounted on the LP, and three $5 \mathrm{~mm}$ ports were placed in the EZ Access. The surgical procedures and instruments were the same as those used for standard laparoscopic surgery with a flexible $5 \mathrm{~mm}$ scope (EndoEye Flex HD; Olympus Corporation, Tokyo, Japan). An additional incision or trocar port was placed without hesitation, if necessary, to complete the procedure, and conversion to open laparotomy was maintained as an option. The decision to use an additional trocar or to convert to open laparotomy depended on the staff surgeon. For lymphadenectomy, a complete mesocolic excision (CME) with central vascular ligation (CVL) was performed (26-28). The final incision was extended to a length comparable to the size of the specimen.

Right hemicolectomy. The patient was placed in the Trendelenburg semi-left lateral position (29). The surgeon and camera operator stood on the left side of the patient. For MLS, the assistant stood between the patient's legs. In both groups, the procedure was performed via an inferior approach, with initial peritoneal dissection between the mesoileum and the retroperitoneum. Following mesocolic plane resection, the duodenum and pancreas were sufficiently exposed, and the ileocolic, right colic (if necessary) and middle colic vessels were ligated and dissected between clips at their origin to allow CME and CVL (Fig. 1). Following the dissection of the greater omentum, the hepatic flexure was mobilized. The specimen was retrieved through the incision of the umbilicus, after which an extracorporeal, functional end-to-end anastomosis was performed.

Sigmoidectomy and anterior resection. The patient was placed in the Trendelenburg semi-right lateral position. The surgeon and camera operator stood on the right side of the patient. For MLS, the assistant stood between the patient's legs or on the left. In both groups, the procedure was performed via a standard medial-to-lateral approach. The inferior mesenteric artery and the inferior mesenteric vein were skeletonized, clipped and divided for CME and CVL (Fig. 2). A downwards dissection from the mesenteric window to the pelvis was then performed. The next step was mobilization of the sigmoid colon up to the splenic flexure. The descending colon and sigmoid colon were pulled anteromedially to ensure preservation of the left ureter and gonadal vessels. The fat surrounding the rectum for $\geq 50 \mathrm{~mm}$ distal to the lesion was dissected and then normally transected using an endoscopic linear stapler (Endo GIA ${ }^{\mathrm{TM}}$;
A

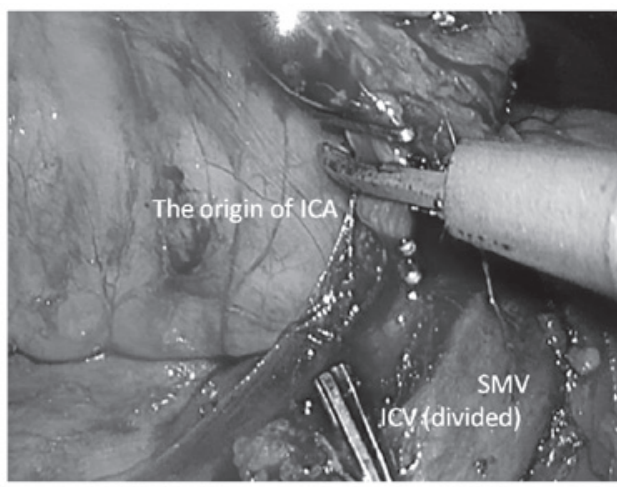

B

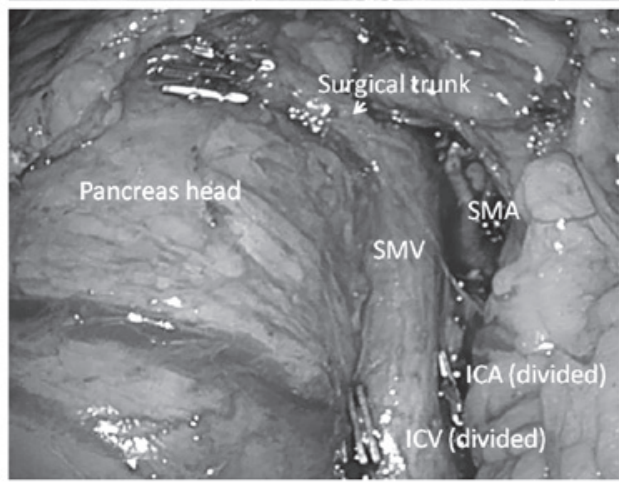

Figure 1. Surgical procedure for right hemicolectomy with complete mesocolic excision for right-sided colon cancer. (A) Exposure and ligation of the origin of the ICA and ICV by complete mesocolic excision with dissection of the entire the right-side mesocolon. (B) Completion of the lymphadenectomy and complete mesocolic excision with central vascular ligation for right-sided colon cancer. ICA, ileocolic artery; ICV, ileocolic vein; SMA, superior mesenteric artery; SMV, superior mesenteric vein.

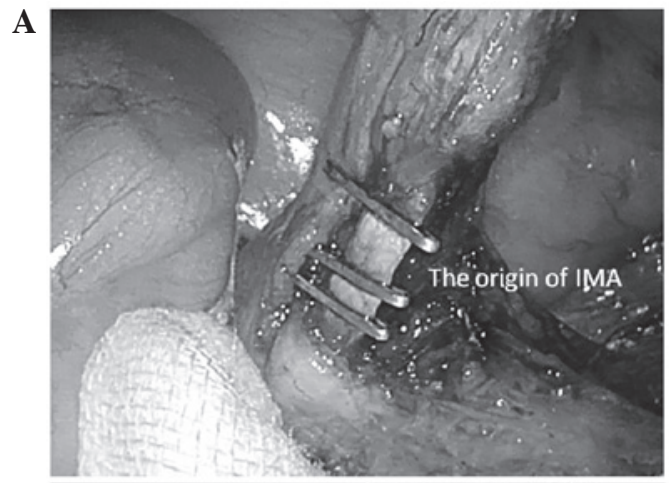

B

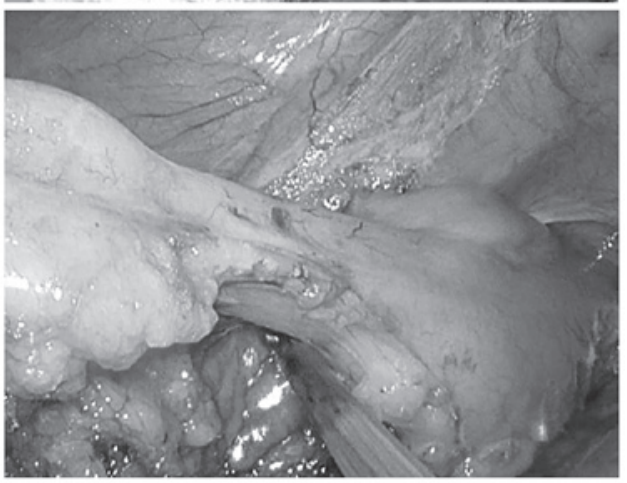

Figure 2. Surgical procedure for sigmoidectomy with complete mesocolic excision for left-sided colon cancer. (A) Exposure and ligation of the origin of the IMA in complete mesocolic excision with central vascular ligation for left-sided colon cancer. (B) The fat surrounding the colon $\geq 5 \mathrm{~cm}$ distal to the lesion was removed and transected intracorporeally. IMA, inferior mesenteric artery. 
Table I. Patient characteristics.

\begin{tabular}{|c|c|c|c|c|c|c|c|c|c|}
\hline \multirow[b]{2}{*}{ Variable } & \multicolumn{3}{|c|}{ Total } & \multicolumn{3}{|c|}{ Right-sided colon cancer } & \multicolumn{3}{|c|}{ Left-sided colon cancer } \\
\hline & $\begin{array}{c}\text { MLS } \\
(n=79)\end{array}$ & $\begin{array}{c}\text { SLS } \\
(n=50)\end{array}$ & $\mathrm{P}$-value & $\begin{array}{l}\text { MLS } \\
(n=36)\end{array}$ & $\begin{array}{c}\text { SLS } \\
(n=27)\end{array}$ & P-value & $\begin{array}{c}\text { MLS } \\
(n=43)\end{array}$ & $\begin{array}{c}\text { SLS } \\
(n=23)\end{array}$ & $\mathrm{P}$-value \\
\hline Age $\left(\right.$ years) ${ }^{\mathrm{a}}$ & $76.9 \pm 5.3$ & $76.6 \pm 4.8$ & 0.73 & $77.8 \pm 5.6$ & $77.7 \pm 5.4$ & 0.96 & $76.1 \pm 4.9$ & $75.1 \pm 3.7$ & 0.44 \\
\hline Gender (n) & & & 0.68 & & & 0.17 & & & 0.54 \\
\hline Male & 44 & 26 & & 15 & 16 & & 29 & 13 & \\
\hline Female & 35 & 24 & & 21 & 11 & & 14 & 10 & \\
\hline $\operatorname{BMI}\left(\mathrm{kg} / \mathrm{m}^{2}\right)^{\mathrm{a}}$ & $22.4 \pm 3.6$ & $22.7 \pm 3.7$ & 0.57 & $21.9 \pm 4.5$ & $23.1 \pm 3.7$ & 0.26 & $22.7 \pm 2.7$ & $22.3 \pm 3.7$ & 0.55 \\
\hline ASA status (n) & & & 0.33 & & & 0.19 & & & 0.82 \\
\hline 1 & 2 & 4 & & 0 & 2 & & 2 & 2 & \\
\hline 2 & 63 & 39 & & 31 & 23 & & 32 & 16 & \\
\hline 3 & 14 & 7 & & 5 & 2 & & 9 & 5 & \\
\hline Prior surgery (n) & 24 & 18 & 0.64 & 7 & 9 & 0.33 & 17 & 9 & 0.82 \\
\hline Tumor location (n) & & & 0.61 & & & & & & \\
\hline Cecum & 11 & 6 & & 11 & 6 & & & & \\
\hline Ascending colon & 16 & 15 & & 16 & 15 & & & & \\
\hline Transverse colon & 9 & 6 & & 9 & 6 & & & & \\
\hline Descending colon & 3 & 2 & & & & & 3 & 2 & \\
\hline Sigmoid colon & 29 & 12 & & & & & 29 & 12 & \\
\hline $\begin{array}{l}\text { Rectosigmoid } \\
\text { colon }\end{array}$ & 11 & 9 & & & & & 11 & 9 & \\
\hline
\end{tabular}

${ }^{a}$ Data presented as the mean \pm standard deviation. All variables were evaluated using a $\chi^{2}$ test or Student's t-test, as appropriate. MLS, multi-port laparoscopic surgery; SLS, single-incision laparoscopic surgery; BMI, body mass index; ASA, American Society of Anesthesiologists.

Medtronic, Minneapolis, MN, USA) with a purple cartridge inserted from the umbilical port with a $12 \mathrm{~mm}$ EZ Link (Hakko Co., Ltd.). The specimen was retrieved through the umbilical incision, and the double stapling technique was applied for anastomosis.

Statistical analysis. Data are presented as the number (n) per group or as the mean \pm standard deviation, accordingly. Statistical analysis was performed using commercially available software (SPSS version 14.0 for Windows; SPSS, Inc., Chicago, IL, USA). All variables were evaluated using a $\chi^{2}$ test or Student's $t$-test, as appropriate. $\mathrm{P}<0.05$ was considered to indicate statistically significant differences.

\section{Results}

Patient characteristics. Patient characteristics did not differ significantly between the MLS and SLS groups: Age, $76.6 \pm 4.8$ vs. $79.6 \pm 12.5$ years, respectively, $\mathrm{P}=0.73$; $\mathrm{BMI}$, $22.4 \pm 3.6$ vs. $22.7 \pm 3.7 \mathrm{~kg} / \mathrm{m}^{2}$, respectively, $\mathrm{P}=0.68$. No other clinical variables, including ASA status, tumor location and history of prior surgery, differed significantly between these two groups. In addition, comparison of these variables between groups on the basis of the tumor location (right and left colon cancer), no differences were found (Table I).

Surgical outcomes. The surgical statistics are listed in Table II. All surgical outcomes, including surgery time, blood loss, hospital stay and delay until first bowel motion, were similar between the MLS and SLS groups. For right-sided colon cancer, surgery time was nearly equivalent in the two groups $(221.3 \pm 69.3$ vs. $217.3 \pm 59.7 \mathrm{~min}$, respectively, $\mathrm{P}=0.80$ ). By contrast, for left-sided colon cancer, surgery time tended to be shorter in the MLS group than in the SLS group (196.3 \pm 51.1 vs. $214.3 \pm 69.7 \mathrm{~min}$, respectively, $\mathrm{P}=0.23)$; however, this difference was non-significant.

The occurrence of surgical complications was nearly equivalent in the two groups $(\mathrm{n}=6$ in both groups; $\mathrm{P}=0.60$ ). The length of hospital stay and the delay until first bowel motion also did not differ significantly between the two groups (10.6 \pm 8.8 vs. $10.1 \pm 10.2$ days, respectively, $\mathrm{P}=0.77 ; 4.1 \pm 3.7$ vs . $4.1 \pm 1.9$ days, respectively, $\mathrm{P}=0.42$ ). For right-sided colon cancer, hospital stay and the delay until first bowel motion appeared to be marginally longer in the MLS group than in SLS group (11.2 \pm 10.7 vs. 8.2 \pm 7.3 days, respectively, $\mathrm{P}=0.22$; $4.3 \pm 2.1$ vs. $4.0 \pm 1.2$ days, respectively, $\mathrm{P}=0.32$ ). By contrast, hospital stay tended to be slightly shorter in the MLS group than in the SLS group for left-sided colon cancer (10.2 \pm 6.9 vs. $12.4 \pm 12.6$ days, respectively, $\mathrm{P}=0.36$ ), whilst delay until first bowel motion was similar $(4.0 \pm 1.5$ vs. $4.0 \pm 2.8$ days, respectively, $\mathrm{P}=0.88$ ).

In 3 patients in the MLS group, the surgery was converted to laparotomy due to bulky lymph node metastases (in 1 case) or intra-abdominal adhesions (in 2 cases); 1 case in the SLS group was converted to laparotomy due to the presence of a congenital bone disorder. In the SLS group, 1 patient 


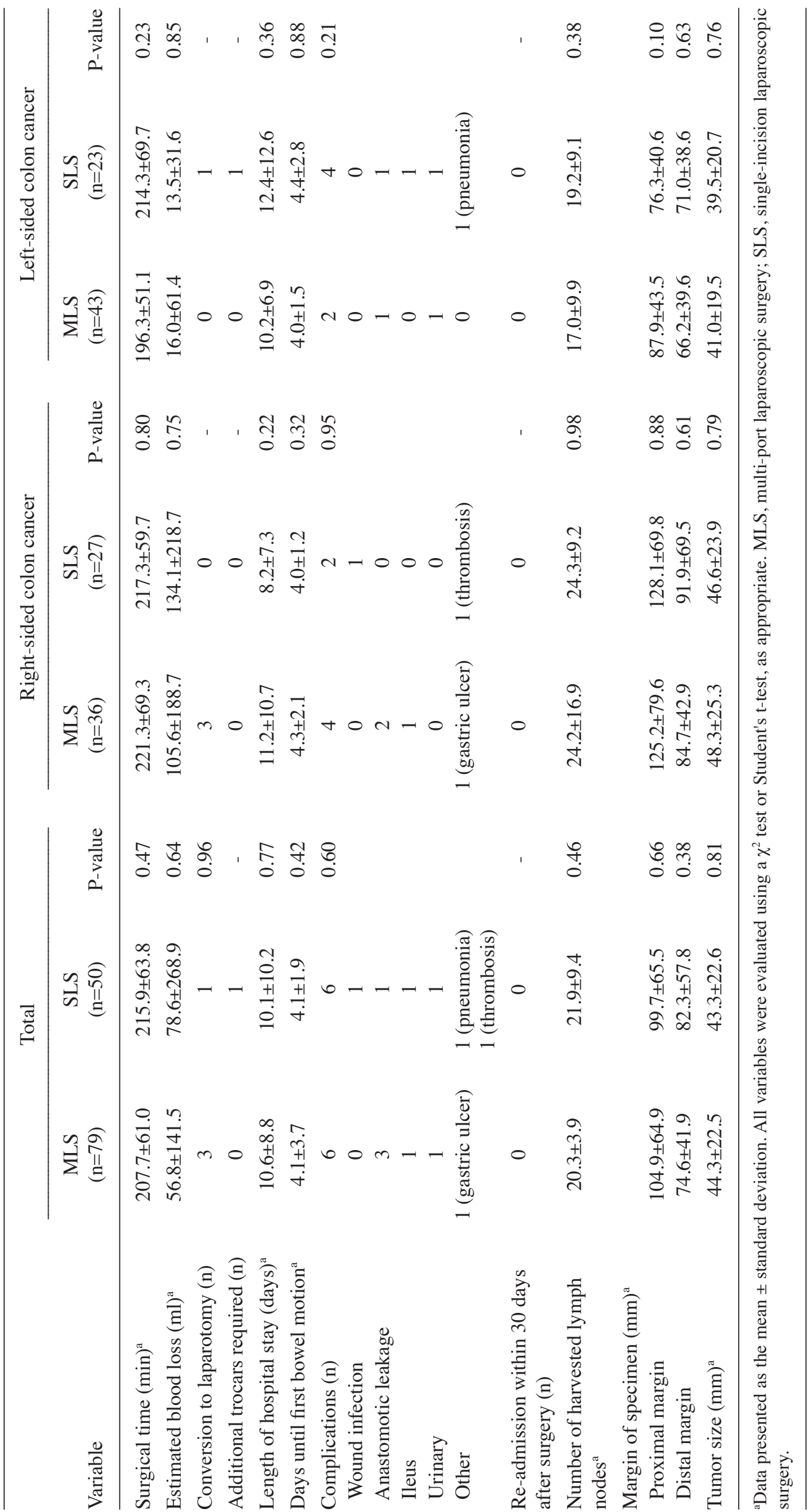


required an additional port due to a rectal injury. There was no mortality in either group, and there was no readmission within 30 days subsequent the procedure. Regarding oncological features, the number of resected lymph nodes, and the resection margin and tumor sizes did not differ significantly between the MLS and SLS groups.

\section{Discussion}

The proportion of elderly patients requiring major abdominal surgery is increasing (24,30). It is clear that, as patients age, there is an associated increase in comorbid conditions that often complicate the perioperative management of elderly patients who undergo major surgery $(24,30)$. MLS is currently considered to be safe and feasible in elderly patients, and evidence has suggested that it is not inferior to the open procedure, as it seems to be less physiologically stressful than conventional open laparotomy $(24,30)$.

SLS offers a potential advantage in the context of minimally invasive surgery. Reduced-port surgery aims to reduce the size and number of ports, preserving the view afforded by the laparoscope while making the surgery less invasive. A number of reports have demonstrated its advantages in reducing the number of laparoscopic ports, including better cosmetic results, reduced postoperative pain and shorter recovery time (31-35). In the current study, no statistically significant differences in short-term outcomes were found between elderly colon cancer patients who underwent MLS and SLS. To the best of our knowledge, this is the first reported case-control study involving elderly patients (mean age, 76.7 years).

The short-term outcomes in this study demonstrated equivalence with the use of SLS and MLS in elderly patients (Table II); the overall morbidities and number of cases with postoperative complications were nearly equivalent in the two groups. The length of hospital stay and the time until the first bowel motion following surgery did not differ significantly between the two groups when patients with left- and right-sided lesions were combined. For right-sided colon cancer, hospital stay and delay until first bowel motion tend to be shorter in the SLS group than in MLS group; however, the differences were non-significant. These findings suggest that SLS may potentially be less invasive for elderly patients with right-sided colon cancer. On the other hand, with left-sided colon cancer, although there was no significant difference, hospital stay was $\sim 2$ days longer in the SLS group than in the MLS group. A possible reason for this may be that the duration of surgery tended to be slightly longer for SLS than for MLS, perhaps related to the trimming of margins on the anal side of the colon, a procedure which tends to take longer during SLS than during MLS. It is thus likely that, if technical development is achieved in the trimming procedure, the difference in the duration of surgery for left-sided colon cancer may decrease. As a result, it may be possible to reduce the difference in the length of hospital stay.

With regard to the oncological quality of the surgery in the present study, the number of resected lymph nodes and resection margins did not differ significantly between the SLS and MLS groups; the mean number of removed lymph nodes was between 17.0 and 24.3 in each group, which is consistent with other studies $(16,17,36)$. Regarding the rate of conversion to laparotomy, the current data indicate conversion rates of 2.0-8.3\% in patients when cases with left- and right-sided colon cancers were combined. The total conversion rate for the 129 patients was $3.1 \%$, which is consistent with previous reports $(16,36,37)$.

The current study has certain limitations. Firstly, the number of cases was insufficient. It is likely that more accurate data could be obtained by increasing the number of cases and conducting an investigation with a large cohort. Secondly, this investigation involved a single institution. Since there were just two surgeons, it is not necessarily the case that similar results would be observed at any institution, and collecting cases from other institutions would produce more universal results. Thirdly, only short-term outcomes are reported, as it was not possible to obtain long-term outcomes. In order to demonstrate that SLS and MLS give similar results in elderly patients, it will be necessary to include a larger number of cases from other institutions, and use a longer observation period in the future.

Despite these limitations, the current observations indicate that SLS has equivalent short-term surgical outcomes to MLS and is oncologically feasible in elderly patients, consistently with the results of previous reports in the general population (16-23). Thus, we believe that these results justify the use of SLS in the routine treatment of elderly patients with colon cancer.

In conclusion, the current study suggests that SLS is equivalent to MLS and is acceptable in elderly patients with cancer.

\section{References}

1. Center MM, Jemal A and Ward E: International trends in colorectal cancer incidence rates. Cancer Epidemiol Biomarkers Prev 18: 1688-1694, 2009.

2. Law WL, Chu KW and Tung PH: Laparoscopic colorectal resection: A safe option for elderly patients. J Am Coll Surg 195: 768-773, 2002.

3. Yasuda K, Sonoda K, Shiroshita H, Inomata M, Shiraishi N and Kitano S: Laparoscopically assisted distal gastrectomy for early gastric cancer in the elderly. Br J Surg 91: 1061-1065, 2004.

4. Choi SI, Lee KY, Park SJ and Lee SH: Single port laparoscopic right hemicolectomy with D3 dissection for advanced colon cancer. World J Gastroenterol 16: 275-278, 2010.

5. Ramos-Valadez DI, Patel CB, Ragupathi M, Bartley Pickron T and Haas EM: Single-incision laparoscopic right hemicolectomy: Safety and feasibility in a series of consecutive cases. Surg Endosc 24: 2613-2616, 2010.

6. Hamzaoglu I, Karahasanoglu T, Baca B, Karatas A, Aytac E and Kahya AS: Single-port laparoscopic sphincter-saving mesorectal excision for rectal cancer: Report of the first 4 human cases. Arch Surg 146: 75-81, 2011.

7. Merchant AM and Lin E: Single-incision laparoscopic right hemicolectomy for a colon mass. Dis Colon Rectum 52: 1021-1024, 2009.

8. Uematsu D, Akiyama G, Matsuura M and Hotta K: Single-access laparoscopic colectomy with a novel multiport device in sigmoid colectomy for colon cancer. Dis Colon Rectum 53: 496-501, 2010.

9. Fiscon V, Portale G, Migliorini G and Frigo F: Laparoscopic resection of colorectal cancer in elderly patients. Tumori 96: 704-708, 2010.

10. Hirano Y, Hattori M, Sato Y, Maeda K, Douden K and Hashizume Y: The outcome of single-incision laparoscopic right colectomy for colon carcinoma in the elderly. Surg Laparosc Endosc Percutan Tech 22: 338-340, 2012.

11. Surgery for colorectal cancer in elderly patients: A systematic review. Lancet 356: 968-974, 2000.

12. Rutten HJ, den Dulk M, Lemmens VE, van de Velde CJ and Marijnen CA: Controversies of total mesorectal excision for rectal cancer in elderly patients. Lancet Oncol 9: 494-501, 2008. 
13. Turrentine FE, Wang H, Simpson VB and Jones RS: Surgical risk factors, morbidity and mortality in elderly patients. J Am Coll Surg 203: 865-877, 2006.

14. Al-Refaie WB, Parsons HM, Habermann EB, Kwaan M, Spencer MP, Henderson WG and Rothenberger DA: Operative outcomes beyond 30-day mortality: Colorectal cancer surgery in oldest old. Ann Surg 253: 947-952, 2011.

15. Panis Y, Maggiori L, Caranhac G, Bretagnol F and Vicaut E: Mortality after colorectal cancer surgery: A French survey of more than 84,000 patients. Ann Surg 254: 738-743; discussion $743-744,2011$

16. A comparison of laparoscopically assisted and open colectomy for colon cancer. N Engl J Med 350: 2050-2059, 2004

17. Guillou PJ, Quirke P, Thorpe H, Walker J, Jayne DG, Smith AM, Heath RM and Brown JM; MRCCLASICC trial group: Short-term endpoints of conventional versus laparoscopic-assisted surgery in patients with colorectal cancer (MRC CLASICC trial): Multicentre, randomised controlled trial. Lancet 365: 1718-1726, 2005.

18. Veldkamp R, Kuhry E, Hop WC, Jeekel J, Kazemier G, Bonjer HJ, Haglind E, Påhlman L, Cuesta MA, Msika S, et al: Laparoscopic surgery versus open surgery for colon cancer: Short-term outcomes of a randomised trial. Lancet Oncol 6: 477-484, 2005.

19. Jayne DG, Guillou PJ, Thorpe H, Quirke P, Copeland J, Smith AM, Heath RM and Brown JM; UK MRC CLASICC Trial Group: Randomized trial of laparoscopic-assisted resection of colorectal carcinoma: 3-year results of the UK MRC CLASICC Trial Group. J Clin Onco 25: 3061-3068, 2007.

20. Colon Cancer Laparoscopic or Open Resection Study Group, Buunen M, Veldkamp R, Hop WC, Kuhry E, Jeekel J, Haglind E, Påhlman L, Cuesta MA, Msika S, et al: Survival after laparoscopic surgery versus open surgery for colon cancer: Long-term outcome of a randomised clinical trial. Lancet Oncol 10: 44-52, 2009.

21. Hemandas AK, Abdelrahman T, Flashman KG, Skull AJ, Senapati A, O'Leary DP and Parvaiz A: Laparoscopic colorectal surgery produces better outcomes for high risk cancer patients compared to open surgery. Ann Surg 252: 84-99, 2010.

22. Bagshaw PF, Allardyce RA, Frampton CM, Frizelle FA Hewett PJ, McMurrick PJ, Rieger NA, Smith JS, Solomon MJ and Stevenson AR; Australasian Laparoscopic Colon Cancer Study Group: Long-term outcomes of the australasian randomized clinical trial comparing laparoscopic and conventional open surgical treatments for colon cancer: The Australasian laparoscopic colon cancer study trial. Ann Surg 256: 915-919, 2012.

23. Cummings LC, Delaney CP and Cooper GS: Laparoscopic versus open colectomy for colon cancer in an older population: A cohort study. World J Surg Oncol 10: 31, 2012.

24. Hinoi T, Kawaguchi Y, Hattori M, Okajima M, Ohdan H, Yamamoto S, Hasegawa H, Horie H, Murata K, Yamaguchi S, et al: Laparoscopic versus open surgery for colorectal cancer in elderly patients: A multicenter matched case-control study. Ann Surg Oncol 22: 2040-250, 2015.

25. Lacy AM, García-Valdecasas JC, Delgado S, Castells A, Taurá P, Piqué JM and Visa J: Laparoscopy-assisted colectomy versus open colectomy for treatment of non-metastatic colon cancer: A randomised trial. Lancet 359: 2224-2229, 2002.
26. Hohenberger W, Weber K, Matzel K, Papadopoulos T and Merkel S: Standardized surgery for colonic cancer: Complete mesocolic excision and central ligation-technical notes and outcome. Colorectal Dis 11: 354-364; discussion 364-365, 2009.

27. West NP, Hohenberger W, Weber K, Perrakis A, Finan PJ and Quirke P: Complete mesocolic excision with central vascular ligation produces an oncologically superior specimen compared with standard surgery for carcinoma of the colon. J Clin Oncol 28: 272-278, 2010.

28. West NP, Kobayashi H, Takahashi K, Perrakis A, Weber K, Hohenberger W, Sugihara K and Quirke P: Understanding optimal colonic cancer surgery: Comparison of Japanese D3 resection and European complete mesocolic excision with central vascular ligation. J Clin Oncol 30: 1763-1769, 2012.

29. Tokuoka M, Ide Y, Yamato H, Uemura M, Hashimoto $Y$, Matsuyama J, Yokoyama S, Morimoto T, Fukushima Y, Nomura T, et al: Single-incision plus one port laparoscopic total pelvic exenteration after neoadjuvant chemotherapy for advanced primary rectal cancer: A case report. Int Sur 100: 1265-1270, 2015.

30. Nakamura T, Mitomi H, Onozato W, Sato T, Ikeda A, Naito M, Ogura N, Kamata H, Ooki A and Watanabe M: Oncological outcomes of laparoscopic surgery in elderly patients with colon cancer: A comparison of patients 64 years or younger with those 75 years or older. Hepatogastroenterology 58: 1200-1204, 2011.

31. Chen WT, Chang SC, Chiang HC, Lo WY, Jeng LB, Wu C and Ke TW: Single-incision laparoscopic versus conventional laparoscopic right hemicolectomy: A comparison of short-term surgical results. Surg Endosc 25: 1887-1892, 2011.

32. Ramos-Valadez DI, Ragupathi M, Nieto J, Patel CB, Miller S, Pickron TB and Haas EM: Single-incision versus conventional laparoscopic sigmoid colectomy: A case-matched series. Surg Endosc 26: 96-102, 2012.

33. Champagne BJ, Lee EC, Leblanc F, Stein SL and Delaney CP: Single-incision vs straight laparoscopic segmental colectomy: A case-controlled study. Dis Colon Rectum 54: 183-186, 2011.

34. Champagne BJ, Papaconstantinou HT, Parmar SS, Nagle DA, Young-Fadok TM, Lee EC and Delaney CP: Single-incision versus standard multiport laparoscopic colectomy: A multicenter, case-controlled comparison. Ann Surg 255: 66-69, 2012.

35. Poon JT, Cheung CW, Fan JK, Lo OS and Law WL: Single-incision versus conventional laparoscopic colectomy for colonic neoplasm: A randomized, controlled trial. Surg Endosc 26: 2729-2734, 2012.

36. Leung KL, Kwok SP, Lam SC, Lee JF, Yiu RY, Ng SS, Lai PB and Lau WY: Laparoscopic resection of rectosigmoid carcinoma: Prospective randomised trial. Lancet 363: 1187-1192, 2004.

37. Veldkamp R, Gholghesaei M, Bonjer HJ, Meijer DW, Buunen M, Jeekel J, Anderberg B, Cuesta MA, Cuschierl A, Fingerhut A, et al: Laparoscopic resection of colon cancer: Consensus of the European association of endoscopic surgery (EAES). Surg Endosc 18: 1163-1185, 2004. 